\title{
FIXED POINTS OF ASYMPTOTICALLY NONEXPANSIVE MAPPINGS IN THE INTERMEDIATE SENSE IN CAT(0) SPACES
}

\author{
Mujahid Abbas, Balwant Singh Thakur, and Dipti Thakur \\ ABSTRACT. The purpose of this paper is to investigate the demiclosed \\ principle, the existence theorems and convergence theorems in $\operatorname{CAT}(0)$ \\ spaces for a class of mappings which is essentially wider than that of \\ asymptotically nonexpansive mappings. The structure of fixed point set \\ of such mappings is also studied. Our results generalize, unify and extend \\ several comparable results in the existing literature.
}

\section{Introduction}

Let $C$ be a nonempty subset of metric space $(X, d)$. Recall that, a mapping $T: C \rightarrow X$ is said to be (i) nonexpansive if $d(T x, T y) \leq d(x, y)$ for all $x, y \in$ $C$ (ii) asymptotically nonexpansive if there exists a sequence $\left\{k_{n}\right\}$ in $[1, \infty)$ with $\lim _{n \rightarrow \infty} k_{n}=1$ such that $d\left(T^{n} x, T^{n} y\right) \leq k_{n} d(x, y)$ for all $x, y$ in $C$ and $n \in \mathbb{N}$, where $\mathbb{N}$ denotes the set of positive integers. Class of asymptotically nonexpansive mappings includes a class of nonexpansive mappings as a proper subclass $([14])$.

In 1993, Bruck, Kuczumow and Reich [4] introduced a notion of asymptotically nonexpansive mapping in the intermediate sense. A mapping $T: C \rightarrow X$ is said to be asymptotically nonexpansive in the intermediate sense if $T$ is uniformly continuous and the following inequality holds:

$$
\limsup _{n \rightarrow \infty} \sup _{x, y \in C}\left\{d\left(T^{n} x, T^{n} y\right)-d(x, y)\right\} \leq 0 .
$$

The concept of asymptotically nonexpansive mappings in the intermediate sense is more general than that of asymptotically nonexpansive mappings.

One of the fundamental and celebrated results in the theory of nonexpansive mappings is Browder's demiclosed principle [3] which states that if $C$ is a nonempty closed convex subset of a uniformly convex Banach space $X$ and

Received February 3, 2012.

2010 Mathematics Subject Classification. 47H09, 47H10.

Key words and phrases. CAT(0) space, asymptotically nonexpansive mapping in the intermediate sense, demiclosed principle, $\Delta$-convergence, iterative approximation, strong convergence, common fixed point. 
$T: C \rightarrow X$ is a nonexpansive mapping, then $I-T$ is demiclosed at each $y \in X$, that is, for any sequence $\left\{x_{n}\right\}$ in $C$ with $x_{n} \rightarrow x$ weakly and $(I-T) x_{n} \rightarrow y$ strongly give $(I-T) x=y$, where $I$ is an identity mapping on $X$.

It is well known that the demiclosed principle plays an important role in studying the asymptotic behavior for nonexpansive mappings (see, for details $[1,13,16])$.

The demiclosed principle for the class of mappings which is essentially wider than that of nonexpansive mappings in the setting of Banach spaces has been studied by several authors (see, for example, [1, 24, 29]). Several papers have been appeared on the iterative approximation of fixed points of nonexpansive, asymptotically nonexpansive and asymptotically nonexpansive mappings in the intermediate sense using Halpern, Mann, Ishikawa iterations in the framework of Hilbert and Banach spaces.

$\mathrm{Xu}$ and Ori [30] introduced an implicit iteration process involving finite family $\left\{T_{i}: i=1,2, \ldots, N\right\}$ of nonexpansive mappings and proved a weak convergence theorem in Hilbert space and posed the following question:

What conditions on the mappings $\left\{T_{i}: i=1,2, \ldots, N\right\}$ and or the control parameter are sufficient to guarantee strong convergence of the sequence.

Several papers deal with an attempt to answer this question in the setting of Hilbert and Banach spaces (see [7, 8, 26, 27] and the references therein).

In recent years, $\mathrm{CAT}(0)$ spaces have attracted the attention of many authors as they have played a very important role in different aspects of geometry ([12]). Kirk $[18,19]$ showed that a nonexpansive mapping defined on a bounded closed convex subset of a complete CAT(0) space has a fixed point. Since then, the fixed point theory in CAT(0) spaces has been rapidly developed. For further details, we refer to $[9,10,11,17,21]$ and references mentioned therein.

The concept of $\triangle$-convergence in general metric spaces was coined by Lim [22]. Kirk and Panyanak [21] specialized this concept to CAT(0) spaces and showed that many Banach space results involving weak convergence have precise analogs in this setting. Dhompongsa and Panyanak [11] continued to work in this direction. Their results involved Mann and Ishikawa iteration schemes involving one mapping.

Motivated by the work of Dhompongsa and Panyanak [11], the purpose of this paper is two fold: We investigate demiclosedness principle, existence theorem, and the structure of fixed point set of asymptotically nonexpansive mapping in the intermediate sense in the framework of CAT(0) spaces. We also study necessary conditions for $\triangle$ and strong convergence of a sequence generated by finite family of asymptotically nonexpansive mappings in the intermediate sense in $\mathrm{CAT}(0)$ spaces.

\section{Preliminaries}

Let $(X, d)$ be a metric space. A geodesic from $x$ to $y$ in $X$ is a map $c$ from a closed interval $[0, l] \subset \mathbb{R}$ to $X$ such that $c(0)=x, c(l)=y$, and 
$d\left(c(t), c\left(t^{\prime}\right)\right)=\left|t-t^{\prime}\right|$ for all $t, t^{\prime} \in[0, l]$. In particular, $c$ is an isometry and $d(x, y)=l$. The image of $c$ is called a geodesic (or metric) segment joining $x$ and $y$. The space $(X, d)$ is said to be a geodesic space if every two point of $X$ are joined by a geodesic and $X$ is said to be uniquely geodesic if there is exactly one geodesic joining $x$ and $y$ for each $x, y \in X$, which we will denote by $[x, y]$, called the segment joining $x$ to $y$.

A geodesic triangle $\Delta\left(x_{1}, x_{2}, x_{3}\right)$ in a geodesic metric space $(X, d)$ consists of three points $x_{1}, x_{2}, x_{3}$ in $X$ (the vertices of $\Delta$ ) and a geodesic segment between each pair of vertices (the edges of $\Delta$ ). A comparison triangle for the geodesic triangle $\triangle\left(x_{1}, x_{2}, x_{3}\right)$ in $(X, d)$ is a triangle $\bar{\Delta}\left(x_{1}, x_{2}, x_{3}\right):=\Delta\left(\bar{x}_{1}, \bar{x}_{2}, \bar{x}_{3}\right)$ in $\mathbb{R}^{2}$ such that $d_{\mathbb{R}^{2}}\left(\bar{x}_{i}, \bar{x}_{j}\right)=d\left(x_{i}, x_{j}\right)$ for $i, j \in\{1,2,3\}$. Such a triangle always exists [20].

A geodesic space is said to be a $\mathrm{CAT}(0)$ space if all geodesic triangles of appropriate size satisfy the following comparison axiom.

$\operatorname{CAT}(0)$ : Let $\triangle$ be a geodesic triangle in $X$ and let $\bar{\Delta}$ be a comparison triangle for $\triangle$. Then $\triangle$ is said to satisfy the $\operatorname{CAT}(0)$ inequality if for all $x, y \in \triangle$ and all comparison points $\bar{x}, \bar{y} \in \bar{\triangle}$,

$$
d(x, y) \leq d_{\mathbb{E}^{2}}(\bar{x}, \bar{y}) .
$$

If $x, y_{1}, y_{2}$ are points in a CAT(0) space and if $y_{0}$ is the midpoint of the segment $\left[y_{1}, y_{2}\right]$, then the $\operatorname{CAT}(0)$ inequality implies

$$
d\left(x, y_{0}\right)^{2} \leq \frac{1}{2} d\left(x, y_{1}\right)^{2}+\frac{1}{2} d\left(x, y_{2}\right)^{2}-\frac{1}{4} d\left(y_{1}, y_{2}\right)^{2} .
$$

This is the $(\mathrm{CN})$ inequality of Bruhat and Tits [5].

CAT(0) spaces may be regarded as a metric version of Hilbert spaces. For example, in any Hilbert space $H$ we have the following extended version of parallelogram law:

$$
\| z-\left(\alpha x+(1-\alpha) y\left\|^{2}=\alpha\right\| z-x\left\|^{2}+(1-\alpha)\right\| z-y\left\|^{2}-\alpha(1-\alpha)\right\| x-y \|^{2}\right.
$$

for any $\alpha \in[0,1]$ and $x, y, z \in H$.

Any CAT(0) metric space $X$ has the inequality

$$
d(z, \alpha x \oplus(1-\alpha) y)^{2} \leq \alpha d(x, z)^{2}+(1-\alpha) d(z, y)^{2}-\alpha(1-\alpha) d(x, y)^{2}
$$

for any $\alpha \in[0,1], x, y \in X$.

If $\alpha=\frac{1}{2}$, then the inequality (2.1) becomes the (CN) inequality.

In fact, a geodesic space is a CAT $(0)$ space if and only if it satisfies the $(\mathrm{CN})$ inequality (cf. [5]). Complete CAT(0) spaces are often called Hadamard spaces. For more on these spaces, please refer to $[2,6]$.

We recall following results from Dhompongsa and Panyanak [11].

Lemma 2.1 ([11, Lemma 2.1(iv)]). For any $x, y \in X$ and $\alpha \in[0,1]$, there exists a unique point $z \in[x, y]$ such that

$$
d(x, z)=\alpha d(x, y) \quad \text { and } \quad d(y, z)=(1-\alpha) d(x, y) .
$$

Notation $(1-\alpha) x \oplus t y$ is used for the unique point $z$ satisfying (2.2). 
Lemma 2.2 ([11, Lemma 2.4]). For $x, y, z \in X$ and $\alpha \in[0,1]$, we have

$$
d(z, \alpha x \oplus(1-\alpha) y) \leq \alpha d(z, x)+(1-\alpha) d(z, y) \quad \forall z \in X .
$$

Let $\left\{x_{n}\right\}$ be a bounded sequence in a closed convex subset $C$ of a $\operatorname{CAT}(0)$ space $X$. For $x \in X$, set

$$
r\left(x,\left\{x_{n}\right\}\right)=\limsup _{n \rightarrow \infty} d\left(x, x_{n}\right) .
$$

The asymptotic radius $r\left(\left\{x_{n}\right\}\right)$ of $\left\{x_{n}\right\}$ is given by

$$
r\left(\left\{x_{n}\right\}\right)=\inf \left\{r\left(x,\left\{x_{n}\right\}\right), x \in X\right\}
$$

and the asymptotic center $A\left(\left\{x_{n}\right\}\right)$ of $\left\{x_{n}\right\}$ is the set

$$
A\left(\left\{x_{n}\right\}\right)=\left\{x \in X: r\left(\left\{x_{n}\right\}=r\left(x,\left\{x_{n}\right\}\right)\right\} .\right.
$$

It is known that, in a $\operatorname{CAT}(0)$ space, $A\left(\left\{x_{n}\right\}\right)$ consists of exactly one point $[10$, Proposition 7].

We now recall the definition of $\Delta$-convergence and weak convergence $(\rightarrow)$ in $\mathrm{CAT}(0)$ space.

Definition 2.3 ([21]). A sequence $\left\{x_{n}\right\}$ in a $\operatorname{CAT}(0)$ space $X$ is said to $\Delta$ converge to $x \in X$ if $x$ is the unique asymptotic center of $\left\{u_{n}\right\}$ for every subsequence $\left\{u_{n}\right\}$ of $\left\{x_{n}\right\}$.

In this case we write $\Delta$ - $\lim _{n} x_{n}=x$ and call $x$ the $\Delta$-limit of $\left\{x_{n}\right\}$.

Recall that a bounded sequence $\left\{x_{n}\right\}$ in $X$ is said to be regular if $r\left(\left\{x_{n}\right\}\right)=$ $r\left(\left\{u_{n}\right\}\right)$ for every subsequence $\left\{u_{n}\right\}$ of $\left\{x_{n}\right\}$. In the Banach space it is known that, every bounded sequence has a regular subsequence [15, Lemma 15.2].

Since in a $\operatorname{CAT}(0)$ space every regular sequence $\Delta$-converges, we see that every bounded sequence in $X$ has a $\Delta$-convergent subsequence, also it is noticed that [21, p. 3690].

Lemma 2.4. Given $\left\{x_{n}\right\} \subset X$ such that $\left\{x_{n}\right\} \Delta$-converges to $x$ and given $y \in X$ with $y \neq x$, then

$$
\limsup _{n} d\left(x_{n}, x\right)<\limsup _{n} d\left(x_{n}, y\right) .
$$

In Banach space above condition is known as the Opial's property.

Now, recall the definition of weak convergence in CAT(0) space.

Definition 2.5 ([17]). Let $C$ be a closed convex subset of a CAT(0) space $X$. A bounded sequence $\left\{x_{n}\right\}$ in $C$ is said to converge weakly to $\omega \in C$ if and only if $\Phi(w)=\inf _{x \in C} \Phi(x)$, where $\Phi(x)=\limsup _{n \rightarrow \infty} d\left(x_{n}, x\right)$.

Note that $\left\{x_{n}\right\} \rightarrow w$ if and only if $A_{C}\left(x_{n}\right)=\{w\}$.

Nanjaras and Panyanak [23] established following relation between $\Delta$-convergence and weak convergence in a $\operatorname{CAT}(0)$ space: 
Lemma 2.6 ([23, Proposition 3.12]). Let $\left\{x_{n}\right\}$ be a bounded sequence in a $C A T(0)$ space $E$ and let $C$ be a closed convex subset of $X$ which contains $\left\{x_{n}\right\}$. Then

(i) $\Delta-\lim _{n} x_{n}=x$ implies $\left\{x_{n}\right\} \rightarrow x$,

(ii) The converse of (i) is true if $\left\{x_{n}\right\}$ is regular.

We now recall some results which play crucial role to prove the main results:

Lemma 2.7 ([11, Lemma 2.8]). If $\left\{x_{n}\right\}$ is a bounded sequence in $X$ with $A\left(\left\{x_{n}\right\}\right)=\{x\}$ and $\left\{u_{n}\right\}$ is a subsequence of $\left\{x_{n}\right\}$ with $A\left(\left\{u_{n}\right\}\right)=\{u\}$ and the sequence $\left\{d\left(x_{n}, u\right)\right\}$ converges, then $x=u$.

Lemma 2.8 ([9, Proposition 2.1]). If $C$ be a closed convex subset of $X$ and if $\left\{x_{n}\right\}$ is a bounded sequence in $C$, then the asymptotic center of $\left\{x_{n}\right\}$ is in $C$.

Lemma 2.9 (Tan and $\mathrm{Xu}[28]$ ). Suppose $\left\{a_{n}\right\}$ and $\left\{b_{n}\right\}$ are two sequences on nonnegative numbers such that $a_{n+1} \leq a_{n}+b_{n}$ for all $n \geq 1$. If $\sum b_{n}$ converges, then $\lim _{n \rightarrow \infty} a_{n}$ exists.

We now define a modified implicit iteration process for finite family of asymptotically nonexpansive mapping in intermediate sense as below:

Let $C$ be a nonempty closed convex subset of a $\mathrm{CAT}(0)$ space $X$, and $\left\{T_{1}, T_{2}, \ldots, T_{N}\right\}$ be a finite family of $N$ asymptotically nonexpansive self mappings on $C$ in the intermediate sense. We generate the sequence $\left\{x_{n}\right\} \subset C$ by

$$
\begin{aligned}
& x_{0} \in K, \\
& x_{1}=\left(1-\alpha_{1}\right) x_{0} \oplus \alpha_{1} T_{1} x_{1}, \\
& x_{2}=\left(1-\alpha_{2}\right) x_{1} \oplus \alpha_{2} T_{2} x_{2}, \\
& \vdots \\
& x_{N}=\left(1-\alpha_{N}\right) x_{N-1} \oplus \alpha_{N} T_{N} x_{N}, \\
& x_{N+1}=\left(1-\alpha_{N+1}\right) x_{N} \oplus \alpha_{N+1} T_{1}^{2} x_{N+1}, \\
& \vdots \\
& x_{2 N}=\left(1-\alpha_{2 N}\right) x_{2 N-1} \oplus \alpha_{2 N} T_{N}^{2} x_{2 N}, \\
& x_{2 N+1}=\left(1-\alpha_{2 N+1}\right) x_{2 N} \oplus \alpha_{2 N+1} T_{1}^{3} x_{2 N+1},
\end{aligned}
$$

where $\left\{\alpha_{n}\right\}$ is an appropriate sequence in $[0,1]$.

We can write down above table in the following compact form:

$$
x_{n}=\left(1-\alpha_{n}\right) x_{n-1} \oplus \alpha_{n} T_{i(n)}^{k(n)} \text { for all } n \geq 1,
$$

where $n=(k(n)-1) N+i(n), k(n) \geq 1$ is a positive integer such that $k(n) \rightarrow \infty$ and $I$ is the index set $\{1,2, \ldots, N\}$. 


\section{Main results}

Denote by Fix $(T)$ the set of fixed points of $T$, that is, Fix $(T)=\{x \in C$ : $T x=x\}$. Put,

$$
C_{n}=\sup _{x, y \in C}\left(d\left(T^{n} x, T^{n} y\right)-d(x, y)\right) \vee 0 .
$$

Theorem 3.1. Let $X$ be a complete $C A T(0)$ space, $C$ a nonempty closed convex subset of $X$. If $T: C \rightarrow C$ is an asymptotically nonexpansive mapping in the intermediate sense, then has a fixed point.

Proof. Let $x \in C$. Define

$$
\Phi(u)=\limsup _{n \rightarrow \infty} d\left(T^{n} x, u\right) \text { for any } u \in C .
$$

Then, we have

$$
d\left(T^{n+m} x, T^{m} u\right) \leq d\left(T^{n} x, u\right)+C_{m}
$$

for any $n, m \geq 1$. On taking limit as $n \rightarrow \infty$, we obtain

$$
\Phi\left(T^{m} u\right) \leq \Phi(u)+C_{m}
$$

for any $m \geq 1$.

Let $w \in C$ be such that $\Phi(w)=\inf \{\Phi(u): u \in C\}=\Phi_{0}$. Then by (3.1), for any $n \geq 1$, we have

$$
\Phi\left(T^{n} w\right) \leq \Phi(w)+C_{n}=\Phi_{0}+C_{n} .
$$

Using inequality $(2.1)$, we obtain

$$
\begin{aligned}
& d\left(T^{n} x, \frac{T^{m} w \oplus T^{h} w}{2}\right)^{2} \\
\leq & \frac{1}{2} d\left(T^{n} x, T^{m} w\right)^{2}+\frac{1}{2} d\left(T^{n} x, T^{h} w\right)^{2}-\frac{1}{4} d\left(T^{m} w, T^{h} w\right)
\end{aligned}
$$

which on taking limit as $n \rightarrow \infty$ gives

$$
\Phi_{0}^{2} \leq \Phi\left(\frac{T^{m} w \oplus T^{h} w}{2}\right)^{2} \leq \frac{1}{2} \Phi\left(T^{m} w\right)^{2}+\frac{1}{2} \Phi\left(T^{h} w\right)^{2}-\frac{1}{4} d\left(T^{m} w, T^{h} w\right)^{2} .
$$

Using (3.2), we have

$$
d\left(T^{m} w, T^{h} w\right)^{2} \leq 2\left(\Phi_{0}+C_{m}\right)^{2}+2\left(\Phi_{0}+C_{h}\right)^{2}-4 \Phi_{0}^{2} .
$$

As $T$ is asymptotically nonexpansive mapping in the intermediate sense, so

$$
\limsup _{m, h \rightarrow \infty}\left(T^{m} w, T^{h} w\right) \leq 0,
$$

which implies that $\left\{T^{n} w\right\}$ is a Cauchy sequence. Let $v=\lim _{n \rightarrow \infty} T^{n} w$. By uniform continuity of $T$, we get $T v=v$.

Theorem 3.2. Let $X$ be a complete $C A T(0)$ space and $C$ be a nonempty closed convex subset of $X$. If $T: C \rightarrow C$ is an asymptotically nonexpansive mapping in the intermediate sense, then Fix(T) is closed and convex. 
Proof. As $T$ is continuous, so $F i x(T)$ is closed. In order to prove $F i x(T)$ is convex, it is enough to prove that $\frac{x \oplus y}{2} \in F i x(T)$ whenever $x, y \in F i x(T)$. Set $w=\frac{x \oplus y}{2}$. For any $n \geq 1$, we have

$$
\begin{aligned}
d\left(T^{n} w, w\right)^{2} & =d\left(T^{n} w, \frac{x \oplus y}{2}\right)^{2} \\
& \leq \frac{1}{2} d\left(x, T^{n} w\right)^{2}+\frac{1}{2} d\left(y, T^{n} w\right)^{2}-\frac{1}{4} d(x, y)^{2}
\end{aligned}
$$

Using (2.3), we obtain

$$
\begin{aligned}
d\left(x, T^{n} w\right)^{2} & =d\left(T^{n} x, T^{n} w\right)^{2} \\
& \leq\left\{d(w, x)+C_{n}\right\}^{2} \\
& =\left\{d\left(\frac{x \oplus y}{2}, x\right)+C_{n}\right\}^{2} \\
& \leq\left\{\frac{1}{2} d(x, y)+C_{n}\right\}^{2} .
\end{aligned}
$$

Similarly,

$$
d\left(y, T^{n} w\right)^{2} \leq\left\{\frac{1}{2} d(x, y)+C_{n}\right\}^{2} .
$$

From (3.3)-(3.5), we get

$$
d\left(T^{n} w, w\right)^{2} \leq C_{n}\left(C_{n}+d(x, y)\right)
$$

for any $n \geq 1$. Hence $\lim _{n \rightarrow \infty} T^{n} w=w$, and $T w=w \in F i x(T)$.

We now prove demiclosed principle for asymptotically nonexpansive mapping in intermediate sense.

Proposition 3.3. Let $C$ be a closed convex subset of a complete $C A T(0)$ space $X$ and $T: C \rightarrow C$ be an asymptotically nonexpansive mapping in the intermediate sense. If $\left\{x_{n}\right\}$ is a bounded sequence in $C$ such that $\lim _{n \rightarrow \infty} d\left(x_{n}, T x_{n}\right)=0$ and $\left\{x_{n}\right\} \rightarrow w$, then $T w=w$.

Proof. Define

$$
\Phi(x)=\limsup _{n \rightarrow \infty} d\left(T^{m} x_{n}, x\right) \text { for all } x \in C \text { and } m \geq 1 .
$$

Then as observed in (3.1), we have

$$
\Phi\left(T^{m} w\right) \leq \Phi(w)+C_{m} \text { for all } m \geq 1 \text { and } w \in C .
$$

Hence

$$
\limsup _{m \rightarrow \infty} \Phi\left(T^{m} w\right) \leq \Phi(w)
$$


Using inequality (2.1), we have

$d\left(T^{m} x_{n}, \frac{w \oplus T^{m} w}{2}\right)^{2} \leq \frac{1}{2} d\left(T^{m} x_{n}, w\right)^{2}+\frac{1}{2} d\left(T^{m} x_{n}, T^{m} w\right)^{2}-\frac{1}{4} d\left(w, T^{m} w\right)^{2}$

for all $n, m \geq 1$. By taking limit as $n \rightarrow \infty$, we get

$$
\Phi\left(\frac{w \oplus T^{m} w}{2}\right)^{2} \leq \frac{1}{2} \Phi(w)^{2}+\frac{1}{2} \Phi\left(T^{m} w\right)^{2}-\frac{1}{4} d\left(w, T^{m} w\right)^{2}
$$

for any $m \geq 1$. As $\left\{x_{n}\right\} \rightarrow w$, so $A\left(\left\{x_{n}\right\}\right)=\{w\}$ and we have

$$
\begin{aligned}
\Phi(w)^{2} & \leq \Phi\left(\frac{w \oplus T^{m} w}{2}\right)^{2} \\
& \leq \frac{1}{2} \Phi(w)^{2}+\frac{1}{2} \Phi\left(T^{m} w\right)^{2}-\frac{1}{4} d\left(w, T^{m} w\right)^{2} .
\end{aligned}
$$

That is,

$$
4 \Phi(w)^{2} \leq 2 \Phi(w)^{2}+2 \Phi\left(T^{m} w\right)^{2}-d\left(w, T^{m} w\right)^{2}
$$

for any $m \geq 1$, which implies that

$$
d\left(w, T^{m} w\right)^{2} \leq 2 \Phi\left(T^{m} w\right)^{2}-2 \Phi(w)^{2} .
$$

By (3.6) and (3.7), we have

$$
\lim _{m \rightarrow \infty} d\left(w, T^{m} w\right)=0
$$

and $T w=w$.

In the light of Lemma 2.6, we get following result from Proposition 3.3.

Corollary 3.4. Let $C$ be a closed convex subset of a $C A T(0)$ space $X$, and $T: C \rightarrow C$ be any asymptotically nonexpansive mapping in the intermediate sense. If bounded sequence $\left\{x_{n}\right\}$ in $C \Delta$-converges to $x$ and $d\left(x_{n}, T x_{n}\right) \rightarrow 0$, then $x \in C$ and $T x=x$.

Now we prove the following lemmas needed in the sequel.

Lemma 3.5. Let $C$ be a nonempty closed convex subset of a complete $C A T(0)$ space $X$ and $\left\{T_{1}, T_{2}, \ldots, T_{N}\right\}: C \rightarrow C$ be $N$ asymptotically nonexpansive mappings in the intermediate sense with

$$
D_{n}=\max \left\{\max _{1 \leq j \leq N} \sup _{x, y \in C}\left(d\left(T_{j}^{n} x, T_{j}^{n} y\right)-d(x, y)\right), 0\right\}
$$

such that $\sum_{n=1}^{\infty} D_{n}<\infty$. Suppose that $x_{0} \in C,\left\{\alpha_{n}\right\}$ is a real sequence in $[a, b]$ for some $a, b \in[0,1]$, and $\left\{x_{n}\right\}$ be the sequence defined by (2.5). If $\mathcal{F}=\bigcap_{i=1}^{N} \operatorname{Fix}\left(T_{i}\right) \neq \emptyset$, then

(i) $\lim _{n \rightarrow \infty} d\left(x_{n}, p\right)$ exists for all $p \in \mathcal{F}$.

(ii) $\lim _{n \rightarrow \infty} d\left(x_{n}, \mathcal{F}\right)$ exists. 
Proof. Take $p \in F i x(T)$ and applying inequality (2.3), we have

$$
\begin{aligned}
d\left(x_{n}, p\right) & =d\left(\left(1-\alpha_{n}\right) x_{n-1} \oplus \alpha_{n} T_{i(n)}^{k(n)} x_{n}, p\right) \\
& \leq\left(1-\alpha_{n}\right) d\left(x_{n-1}, p\right)+\alpha_{n} d\left(T_{i(n)}^{k(n)} x_{n}, p\right) \\
& \leq\left(1-\alpha_{n}\right) d\left(x_{n-1}, p\right)+\alpha_{n}\left(D_{n}+d\left(x_{n}, p\right)\right) \\
& =d\left(x_{n-1}, p\right)+\frac{\alpha_{n}}{1-\alpha_{n}} D_{n} \\
& \leq d\left(x_{n-1}, p\right)+\frac{b}{1-b} D_{n} .
\end{aligned}
$$

Taking infimum over all $p \in \mathcal{F}$, we have

$$
d\left(x_{n}, \mathcal{F}\right) \leq d\left(x_{n-1}, \mathcal{F}\right)+\frac{b}{1-b} D_{n} .
$$

It follow from Lemma 2.9, and (3.8) and (3.9) that $\lim _{n \rightarrow \infty} d\left(x_{n}, p\right)$ and $\lim _{n \rightarrow \infty} d\left(x_{n}, \mathcal{F}\right)$ exists.

Lemma 3.6. Let $C$ be a nonempty closed convex subset of a complete $C A T(0)$ space $X$ and $\left\{T_{1}, T_{2}, \ldots, T_{N}\right\}: C \rightarrow C$ be $N$ asymptotically nonexpansive mappings in the intermediate sense with

$$
D_{n}=\max \left\{\max _{1 \leq j \leq N} \sup _{x, y \in C}\left(d\left(T_{j}^{n} x, T_{j}^{n} y\right)-d(x, y)\right), 0\right\}
$$

such that $\sum_{n=1}^{\infty} D_{n}<\infty$. Suppose that $x_{0} \in C,\left\{\alpha_{n}\right\}$ is a real sequence in $[a, b]$ for some $a, b \in(0,1)$, and $\left\{x_{n}\right\}$ be the sequence defined by (2.5). If $\mathcal{F}=\bigcap_{i=1}^{N} \operatorname{Fix}\left(T_{i}\right) \neq \emptyset$, then $\lim _{n \rightarrow \infty} d\left(x_{n}, T_{i} x_{n}\right)=0$ for all $i \in\{1,2, \ldots, N\}$.

Proof. Using (2.5) and (2.1), we have

$$
\begin{aligned}
d^{2}\left(x_{n}, p\right)= & d^{2}\left(\left(1-\alpha_{n}\right) x_{n-1} \oplus \alpha_{n} T_{i(n)}^{k(n)} x_{n}, p\right) \\
\leq & \alpha_{n} d^{2}\left(T_{i(n)}^{k(n)} x_{n}, p\right)+\left(1-\alpha_{n}\right) d^{2}\left(x_{n-1}, p\right) \\
& \quad-\alpha_{n}\left(1-\alpha_{n}\right) d^{2}\left(T_{i(n)}^{k(n)} x_{n}, x_{n-1}\right) \\
\leq & \alpha_{n}\left[D_{k(n)}+d\left(x_{n}, p\right)\right]^{2}+\left(1-\alpha_{n}\right) d^{2}\left(x_{n-1}, p\right) \\
& -\alpha_{n}\left(1-\alpha_{n}\right) d^{2}\left(T_{i(n)}^{k(n)} x_{n}, x_{n-1}\right) \\
= & \frac{\alpha_{n}}{1-\alpha_{n}}\left[D_{k(n)}^{2}+2 D_{k(n)} d\left(x_{n}, p\right)\right]+d^{2}\left(x_{n-1}, p\right) \\
& -\alpha_{n} d^{2}\left(T_{i(n)}^{k(n)} x_{n}, x_{n-1}\right)
\end{aligned}
$$


which on simplification implies that

$$
\begin{aligned}
& d^{2}\left(T_{i(n)}^{k(n)} x_{n}, x_{n-1}\right) \\
\leq & \frac{1}{1-\alpha_{n}}\left[D_{k(n)}^{2}+2 D_{k(n)} d\left(x_{n}, p\right)\right]+\frac{1}{\alpha_{n}}\left[d^{2}\left(x_{n-1}, p\right)-d^{2}\left(x_{n}, p\right)\right] \\
\leq & \frac{1}{1-b}\left[D_{k(n)}^{2}+2 D_{k(n)} d\left(x_{n}, p\right)\right]+\frac{1}{a}\left[d^{2}\left(x_{n-1}, p\right)-d^{2}\left(x_{n}, p\right)\right] .
\end{aligned}
$$

Since $D_{n} \rightarrow 0$ as $n \rightarrow \infty$ and $d\left(x_{n}, p\right)$ is convergent, therefore on taking limit as $n \rightarrow \infty$, we get

$$
\lim _{n \rightarrow \infty} d\left(T_{i(n)}^{k(n)} x_{n}, x_{n-1}\right)=0
$$

Moreover

$$
\begin{aligned}
d\left(x_{n}, x_{n-1}\right) & \leq d\left(\left(1-\alpha_{n}\right) x_{n-1} \oplus \alpha_{n} T_{i(n)}^{k(n)} x_{n}, x_{n-1}\right) \\
& \leq\left(1-\alpha_{n}\right) d\left(x_{n-1}, x_{n-1}\right)+\alpha_{n} d\left(T_{i(n)}^{k(n)} x_{n}, x_{n-1}\right)
\end{aligned}
$$

implies

$$
\lim _{n \rightarrow \infty} d\left(x_{n}, x_{n-1}\right)=0 .
$$

From (3.10) and (3.11), we have

$$
\lim _{n \rightarrow \infty} d\left(T_{i(n)}^{k(n)} x_{n}, x_{n}\right) \leq \lim _{n \rightarrow \infty}\left\{d\left(T_{i(n)}^{k(n)} x_{n}, x_{n-1}\right)+d\left(x_{n}, x_{n-1}\right)\right\}=0
$$

and

$$
\lim _{n \rightarrow \infty} d\left(x_{n}, x_{n+j}\right)=0 \quad \forall j=1,2, \ldots
$$

Letting $\sigma_{n}=d\left(T_{i(n)}^{k(n)} x_{n}, x_{n}\right)$, by (3.12), we have $\sigma_{n} \rightarrow 0$.

Since for each $n>N$, we have $n=(k(n)-1)+i(n)$ where $i(n) \in\{1,2, \ldots$, $N\}$, also $i(n)=i(n+N)$ and $k(n)+1=k(n+N)$, so we have

$$
\begin{aligned}
d\left(x_{n}, T_{n} x_{n}\right) \leq & d\left(x_{n}, x_{n+N}\right)+d\left(x_{n+N}, T_{i(n)}^{k(n)+1} x_{n+N}\right) \\
& +d\left(T_{i(n)+1}^{k(n)+1} x_{n+N}, T_{i(n)}^{k(n)+1} x_{n}\right)+d\left(T_{i(n)}^{k(n)+1} x_{n}, T_{n} x_{n}\right) \\
= & d\left(x_{n}, x_{n+N}\right)+d\left(x_{n+N}, T_{i(n+N)}^{k(n+N)} x_{n+N}\right) \\
& +d\left(T_{i(n+N)}^{k(n+N)} x_{n+N}, T_{i(n+N)}^{k(n+N)} x_{n}\right)+d\left(T_{i(n)}^{k(n)+1} x_{n}, T_{i(n)} x_{n}\right) \\
\leq & \sigma_{n+N}+D_{k(n+N)}+2 d\left(x_{n}, x_{n+N}\right)+d\left(T_{i(n)}^{k(n)+1} x_{n}, T_{i(n)} x_{n}\right) \\
\rightarrow & 0 \text { as } n \rightarrow \infty
\end{aligned}
$$

by (3.12), (3.13) and uniform continuity of $T_{i(n)}$. 
Consequently, for any $j=1,2, \ldots, N$, from (3.13), (3.14) and uniform continuity of $T_{i(n)}$, we have

$$
\begin{aligned}
d\left(x_{n}, T_{n+j} x_{n}\right) & \leq d\left(x_{n}, x_{n+j}\right)+d\left(x_{n+j}, T_{n+j} x_{n+j}\right)+d\left(T_{n+j} x_{n+j}, T_{n+j} x_{n}\right) \\
& \rightarrow 0 \text { as } n \rightarrow \infty .
\end{aligned}
$$

This implies that the sequence

$$
\bigcup_{j=1}^{N}\left\{d\left(x_{n}, T_{n+j} x_{n}\right)\right\}_{n=1}^{\infty} \rightarrow 0 \text { as } n \rightarrow \infty .
$$

Since for each $l=1,2, \ldots, N, \quad\left\{d\left(x_{n}, T_{l} x_{n}\right)\right\}_{n=1}^{\infty}$ is a subsequence of $\bigcup_{j=1}^{N}\left\{d\left(x_{n}\right.\right.$, $\left.\left.T_{n+j} x_{n}\right)\right\}_{n=1}^{\infty}$, therefore we have

$$
\lim _{n \rightarrow \infty} d\left(x_{n}, T_{l} x_{n}\right)=0 \quad \text { for all } l=1,2, \ldots, N .
$$

Now we prove the $\Delta$-convergence and strong convergence results.

Theorem 3.7. Let $C$ be a nonempty closed convex subset of a complete $C A T(0)$ space $X$ and $\left\{T_{1}, T_{2}, \ldots, T_{N}\right\}: C \rightarrow C$ be $N$ asymptotically nonexpansive mappings in the intermediate sense with

$$
D_{n}=\max \left\{\max _{1 \leq j \leq N} \sup _{x, y \in C}\left(d\left(T_{j}^{n} x, T_{j}^{n} y\right)-d(x, y)\right), 0\right\}
$$

such that $\sum_{n=1}^{\infty} D_{n}<\infty$. Suppose that $x_{0} \in C,\left\{\alpha_{n}\right\}$ is a real sequence in $[a, b]$ for some $a, b \in(0,1)$, and $\left\{x_{n}\right\}$ be the sequence defined by (2.5). If $\mathcal{F}=\bigcap_{i=1}^{N} \operatorname{Fix}\left(T_{i}\right) \neq \emptyset$, then $\left\{x_{n}\right\}$ is $\Delta$-convergent to an element of $\mathcal{F}$.

Proof. We first show that $w_{w}\left(\left\{x_{n}\right\}\right) \subseteq \mathcal{F}$. Let $u \in w_{w}\left(\left\{x_{n}\right\}\right)$, then there exists a subsequence $\left\{u_{n}\right\}$ of $\left\{x_{n}\right\}$ such that $A\left(\left\{x_{n}\right\}\right)=\{u\}$. By Lemma 2.8, there exists a subsequence $\left\{v_{n}\right\}$ of $\left\{u_{n}\right\}$ such that $\Delta-\lim _{n} v_{n}=v \in C$. By Corollary 3.4, $v \in F\left(T_{l}\right)$. By arbitrariness of $l \in\{1,2, \ldots, N\}$, we have $v \in \mathcal{F}$. By Lemma $3.5 \lim _{n \rightarrow \infty} d\left(x_{n}, v\right)$ exists so by Lemma 2.7 , we have $u=v$, i.e., $w_{w}\left(\left\{x_{n}\right\}\right) \subseteq \mathcal{F}$.

To show that $\left\{x_{n}\right\} \Delta$-converges to a point in $\mathcal{F}$, it is enough to show that $w_{w}\left(\left\{x_{n}\right\}\right)$ consists of exactly one point.

Let $\left\{u_{n}\right\}$ be a subsequence of $\left\{x_{n}\right\}$ with $A\left(\left\{u_{n}\right\}\right)=\{u\}$ and let $A\left(\left\{x_{n}\right\}\right)=$ $\{x\}$ for some $u \in w_{w}\left(\left\{x_{n}\right\}\right) \subseteq \mathcal{F}$ and $\left\{d\left(x_{n}, v\right)\right\}$ converges. By Lemma 2.7, we have $x=v \in \mathcal{F}$. Thus $w_{w}\left(\left\{x_{n}\right\}\right)=\{x\}$.

This completes the proof.

Theorem 3.8. Let $C$ be a nonempty closed convex subset of a complete $C A T(0)$ space $X$ and $\left\{T_{1}, T_{2}, \ldots, T_{N}\right\}: C \rightarrow C$ be $N$ asymptotically nonexpansive mappings in the intermediate sense with

$$
D_{n}=\max \left\{\max _{1 \leq j \leq N} \sup _{x, y \in C}\left(d\left(T_{j}^{n} x, T_{j}^{n} y\right)-d(x, y)\right), 0\right\}
$$


such that $\sum_{n=1}^{\infty} D_{n}<\infty$. Suppose that $x_{0} \in C,\left\{\alpha_{n}\right\}$ is a real sequence in $[a, b]$ for some $a, b \in(0,1)$, and $\left\{x_{n}\right\}$ be the sequence defined by (2.5). Then $\left\{x_{n}\right\}$ converges strongly to a common fixed point of $\left\{T_{i}: i=1,2, \ldots, N\right\}$ if and only if $\liminf _{n \rightarrow \infty} d\left(x_{n}, \mathcal{F}\right)=0$.

Proof. Necessity is obvious.

To prove the sufficiency, suppose that $\liminf _{n \rightarrow \infty} d\left(x_{n}, \mathcal{F}\right)=0$, also

$$
\lim _{n \rightarrow \infty} d\left(x_{n}, \mathcal{F}\right)
$$

exists by Lemma 3.5(ii). Hence by hypothesis $\lim _{n \rightarrow \infty} d\left(x_{n}, \mathcal{F}\right)=0$.

Thus for arbitrary $\varepsilon>0$, there exists a positive integer $n_{1}$ such that for all $n \geq n_{1}$

In particular,

$$
d\left(x_{n}, \mathcal{F}\right)<\frac{\varepsilon}{8}
$$

Thus there must exist $p^{*} \in \mathcal{F}$ such that

$$
\inf \left\{d\left(x_{n_{1}}, p\right): p \in \mathcal{F}\right\}<\frac{\varepsilon}{8} .
$$

$$
d\left(x_{n_{1}}, p^{*}\right)<\frac{\varepsilon}{4} .
$$

Furthermore $\sum_{n=1}^{\infty} D_{n}<\infty$ implies that there exists a positive integer $n_{2}$ such that $\sum_{n=1}^{\infty} D_{n}<\frac{\varepsilon}{4 M}$ for some positive integer $M$. Let $n_{0}=\max \left\{n_{1}, n_{2}\right\}$.

For each $m, n \geq n_{0}$, it follows from (3.8), that

$$
\begin{aligned}
d\left(x_{n}, x_{m}\right) & \leq d\left(x_{n}, p^{*}\right)+d\left(x_{m}, p^{*}\right) \\
& \leq d\left(x_{n_{0}}, p^{*}\right)+M \sum_{n_{0}+1}^{n} D_{j}+d\left(x_{n_{0}}, p^{*}\right)+M \sum_{n_{0}+1}^{m} D_{j} \\
& \leq 2 d\left(x_{n_{0}}, p^{*}\right)+2 M \sum_{n_{0}+1}^{n} D_{j} \\
& <\varepsilon .
\end{aligned}
$$

Hence $\left\{x_{n}\right\}$ is a Cauchy sequence in a closed subset $C$ of a complete CAT $(0)$ space and so converges to some $q \in C$. Since $\lim _{n \rightarrow \infty} d\left(x_{n}, \mathcal{F}\right)=0$ we get $d(q, \mathcal{F})=0$, closedness of $\mathcal{F}$ gives that $q \in \mathcal{F}$.

A mapping $T: C \rightarrow C$ is called semi-compact if any sequence $\left\{x_{n}\right\}$ in $C$ satisfying $d\left(x_{n}, T x_{n}\right) \rightarrow 0$ as $n \rightarrow \infty$ has a convergent subsequence.

A mapping $T: C \rightarrow C$ is said to satisfy Condition-I if there is a nondecreasing function $f:[0, \infty) \rightarrow[0, \infty)$ with $f(0)=0$ and $f(r)>r$ for all $r \in(0, \infty)$ such that for all $x \in C$

$$
\|x-T x\| \geq f(d(x, F(T))),
$$

where $d(x, F(T))=\inf \left\{\left\|x-x^{*}\right\|: x^{*} \in F(T) \neq \emptyset\right\}$. Condition-I was introduced by Senter and Dotson [25].

We now give strong convergence result employing Condition-I. 
Theorem 3.9. Let $C$ be a nonempty closed convex subset of a complete $C A T(0)$ space $X$ and $\left\{T_{1}, T_{2}, \ldots, T_{N}\right\}: C \rightarrow C$ be $N$ asymptotically nonexpansive mappings in the intermediate sense with

$$
D_{n}=\max \left\{\max _{1 \leq j \leq N} \sup _{x, y \in C}\left(d\left(T_{j}^{n} x, T_{j}^{n} y\right)-d(x, y)\right), 0\right\}
$$

such that $\sum_{n=1}^{\infty} D_{n}<\infty$. Suppose that $x_{0} \in C,\left\{\alpha_{n}\right\}$ is a real sequence in $[a, b]$ for some $a, b \in(0,1)$, and $\left\{x_{n}\right\}$ be the sequence defined by (2.5). If at least one of the mappings in $\left\{T_{1}, T_{2}, \ldots, T_{N}\right\}$ satisfies Condition-I, then $\left\{x_{n}\right\}$ converges strongly to a common fixed point of $\left\{T_{i}: i=1,2, \ldots, N\right\}$.

Proof. By Lemma 3.6, we see for $x^{*} \in \mathcal{F}$ that

$$
\lim _{n \rightarrow \infty} d\left(x_{n}, x^{*}\right) \text { and } \lim _{n \rightarrow \infty} d\left(x_{n}, \mathcal{F}\right) \text { exist. }
$$

Let one of $T_{i}^{\prime}$ s, say $T_{s}, s \in\{1,2, \ldots, N\}$ satisfy Condition-I. By Lemma 3.6, $\lim _{n \rightarrow \infty} d\left(x_{n}, T_{s} x_{n}\right)=0$, so we have $\lim _{n \rightarrow \infty} f\left(d\left(x_{n}, \mathcal{F}\right)\right)=0$. By the nature of $\mathcal{F}$ and the fact that $\lim _{n \rightarrow \infty} d\left(x_{n}, \mathcal{F}\right)$ exists, we have $\lim _{n \rightarrow \infty} d\left(x_{n}, \mathcal{F}\right)=0$ and the result follows from Theorem 3.8 .

Theorem 3.10. Let $C$ be a nonempty closed convex subset of a complete $C A T(0)$ space $X$ and let $\left\{T_{1}, T_{2}, \ldots, T_{N}\right\}: C \rightarrow C$ be $N$ asymptotically nonexpansive mappings in the intermediate sense with

$$
D_{n}=\max \left\{\max _{1 \leq j \leq N} \sup _{x, y \in C}\left(d\left(T_{j}^{n} x, T_{j}^{n} y\right)-d(x, y)\right), 0\right\}
$$

such that $\sum_{n=1}^{\infty} D_{n}<\infty$. Suppose that $x_{0} \in C,\left\{\alpha_{n}\right\}$ is a real sequence in $[a, b]$ for some $a, b \in(0,1)$, and $\left\{x_{n}\right\}$ be the sequence defined by (2.5). If any one of the mappings in $\left\{T_{1}, T_{2}, \ldots, T_{N}\right\}$ is semicompact, then $\left\{x_{n}\right\}$ converges strongly to a common fixed point of $\left\{T_{i}: i=1,2, \ldots, N\right\}$.

Proof. Suppose that $T_{i_{0}}$ is semi-compact for some $i_{0} \in\{1,2, \ldots, N\}$. By Lemma 3.6, we have $\lim _{n \rightarrow \infty} d\left(x_{n}, T_{i_{0}} x_{n}\right)=0$. So there exists a subsequence $\left\{x_{n_{j}}\right\}$ of $\left\{x_{n}\right\}$ such that $\lim _{n_{j} \rightarrow \infty} x_{n_{j}} \rightarrow p \in C$. Now Lemma 3.6 guarantees that $\lim _{n_{j} \rightarrow \infty} d\left(x_{n_{j}}, T_{l} x_{n_{j}}\right)=0$ for all $l \in\{1,2, \ldots, N\}$ and so $d\left(p, T_{i} p\right)=0$ for all $l \in\{1,2, \ldots, N\}$. This implies that $p \in \mathcal{F}$. Since $\lim _{n \rightarrow \infty} d\left(x_{n}, \mathcal{F}\right)=0$, if follows, as in the proof of Theorem 3.8, that $\left\{x_{n}\right\}$ converges strongly to some common fixed point in $\mathcal{F}$.

This completes the proof.

Remark 3.11. Any $\operatorname{CAT}(\kappa)$ space is a $\operatorname{CAT}\left(\kappa^{\prime}\right)$ space for every $\kappa^{\prime}>\kappa[2$, page $165]$, therefore the results in this paper can be applied to any $\operatorname{CAT}(\kappa)$ space with $\kappa<0$. 


\section{References}

[1] R. P. Agarwal, D. O'Regan, and D. R. Sahu, Fixed point theory for Lipschitzian-type mappings with applications, Topological Fixed Point Theory and Its Applications 6, Springer, New York, 2009.

[2] M. Bridson and A. Haeflinger, Metric Spaces of Non-positive Curvature, Springer-Verlag, Berlin, 1999.

[3] F. E. Browder, Semicontractive and semiaccretive nonlinear mappings in Banach spaces, Bull. Amer. Math. Soc. 74 (1968), 660-665.

[4] R. E. Bruck, Y. Kuczumow, and S. Reich, Convergence of iterates of asymptotically nonexpansive mappings in Banach spaces with the uniform Opial property, Colloq. Math. 65 (1993), no. 2, 169-179.

[5] F. Bruhat and J. Tits, Groupes réductifs sur un corps local, Inst. Hautes Études Sci. Publ. Math. 41 (1972), 5-251.

[6] D. Burago, Y. Burago, and S. Ivanov, A Course in Metric Geometry, in: Graduate Studies in Mathematics, Vol. 33, Americal Mathematical Society, Providence, RI, 2001.

7] S. S. Chang, K. K. Tan, H. W. J. Lee, and C. K. Chan, On the convergence of implicit iteration process with error for a finite family of asymptotically nonexpansive mappings, J. Math. Anal. Appl. 313 (2006), no. 1, 273-283.

[8] C. E. Chidume and N. Shahzad, Strong convergence of an implicit iteration process for a finite family of nonexpansive mappings, Nonlinear Anal. 62 (2005), no. 6, 1149-1156.

[9] S. Dhompongsa, W. A. Kirk, and B. Panyanak, Nonexpansive set-valued mappings in metric and Banach spaces, J. Nonlinear Convex Anal. 8 (2007), no. 1, 35-45.

[10] S. Dhompongsa, W. A. Kirk, and B. Sims, Fixed points of uniformly lipschitzian mappings, Nonlinear Anal. 65 (2006), no. 4, 762-772.

[11] S. Dhompongsa and B. Panyanak, On $\Delta$-convergence theorem in CAT(0) spaces, Comput. Math. Appl. 56 (2008), no. 10, 2572-2579.

[12] R. Espinola and A. Nicolae, Geodesic Ptolemy spaces and fixed points, Nonlinear Anal. 74 (2011), no. 1, 27-34.

[13] H. Fukhar-ud-din and S. H. Khan, Convergence of iterates with errors of asymptotically quasi-nonexpansive mappings and applications, J. Math. Anal. Appl. 328 (2007), no. 2, $821-829$.

[14] K. Goebel and W. A. Kirk, A fixed point theorem for asymptotically nonexpansive mappings, Proc. Amer. Math. Soc. 35 (1972), 171-174.

[15] _ Topics in Metric Fixed Point Theory, Cambridge University Press, Cambridge, 1990

[16] K. Goebel and S. Reich, Uniform convexity, hyperbolic geometry, and nonexpansive mappings, Marcel Dekker, Inc., New York, 1984.

[17] N. Hussain and M. A. Khamsi, On asymptotic pointwise contractions in metric spaces, Nonlinear Anal. 71 (2009), no. 10, 4423-4429.

[18] W. A. Kirk, Geodesic geometry and fixed point theory, in Seminar of Mathematical Analysis (Malaga/Seville, 2002/2003), Vol.64, Colecci ón Abierta, pp.195-225, University de Sevilla, Secretariado de Publicaciones, Sevilla, Spain, 2003.

[19] _ Geodesic geometry and fixed point theory II, in International Conference on Fixed Point Theory and Applications, pp. 113-142, Yokohama Publishers, Yokohama, Japan, 2004

[20] Fixed point theorems in $C A T(0)$ spaces and $\mathbb{R}$-trees, Fixed Point Theory Appl. 2004 (2004), no. 4, 309-316.

[21] W. A. Kirk and B. Panyanak, A concept of convergence in geodesic spaces, Nonlinear Anal. 68 (2008), no. 12, 3689-3696.

[22] T. C. Lim, Remarks on some fixed point theorems, Proc. Amer. Math. Soc. 60 (1976), 179-182. 
[23] B. Nanjaras and B. Panyanak, Demiclosed principle for asymptotically nonexpansive mappings in CAT(0) spaces, Fixed Point Theory Appl. 2010 (2010), Art. ID 268780, $14 \mathrm{pp}$.

[24] D. R. Sahu and I. Beg, Weak and strong convergence for fixed points of nearly asymptotically non-expansive mappings, Int. J. Mod. Math. 3 (2008), no. 2, 135-151.

[25] H. F. Senter and W. G. Dotson, Jr., Approximating fixed points of nonexpansive mappings, Proc. Amer. Math. Soc. 44 (1974), 375-380.

[26] N. Shahzad and H. Zegeye, Strong convergence of an implicit iteration process for a finite family of generalized asymptotically quasi-nonexpansive maps, Appl. Math. Comput. 189 (2007), no. 2, 1058-1065.

[27] Z. H. Sun, Strong Convergence of an implicit iteration process for a finite family of asymptotically quasi-nonexpansive mappings, J. Math. Anal. Appl. 286 (2003), no. 1, 351-358.

[28] K. K. Tan and H. K. Xu, Approximating fixed points of nonexpansive mappings by the Ishikawa iteration process, J. Math. Anal. Appl. 178 (1993), no. 2, 301-308.

[29] H. K. Xu, Existence and convergence for fixed points of mappings of asymptotically nonexpansive type, Nonlinear Anal. 16 (1991), no. 12, 1139-1146.

[30] H. K. Xu and R. G. Ori, An implicit iteration process for nonexpansive mappings, Numer. Funct. Anal. Optim. 22 (2001), no. 5-6, 767-773.

Mujahid AbBas

Department of Mathematics

Lahore University of Management SCIEnCES

54792-LAHORE, PAKISTAN

E-mail address: mujahid@lums.edu.pk

Balwant Singh Thakur

School of Studies in Mathematics

Pt.Ravishankar Shukla University

RAIPUR 492010, INDIA

E-mail address: balwantst@gmail.com

Dipti ThakuR

School of Studies in Mathematics

Pt.Ravishankar Shukla University

RAIPUR 492010, INDIA 